\title{
ANTHROPOMETRIC MEASUREMENT OF CORNEAL CURVATURE BY KERATOMETRY IN ADULT CENTRAL INDIAN POPULATION
}

\section{Jagriti Agrawal ${ }^{* 1}$, Pawan Kumar N ${ }^{2}$, Pradep Jain ${ }^{3}$.}

${ }^{{ }^{*} 1}$ Department Of Anatomy, Pt.J.N.M Medical College, Raipur Chhattisgarh, India.

${ }^{2}$ Department Of Anatomy, Pt.J.N.M Medical College, Raipur Chhattisgarh, India.

${ }^{3}$ Department Of Anatomy, Pt.J.N.M Medical College, Raipur Chhattisgarh, India.

\section{ABSTRACT}

Background: Global advances in ophthalmology have created a greater need for ocular parameters in different clinical and diagnostic fields. One important ophthalmic parameter is the curvature of cornea which is commonly needed for intraocular lens power calculation before cataract and refractive surgery and helps ophthalmologists in contact lens fitting, diagnosis of several eye conditions such as keratoconus, keratoglobus and Marfan's syndrome.

Subjects and Methods: The data for the study were retrospectively collected from the case files of patients who had undergone cataract surgery from January 2017 to July 2017 in a private eye hospital Raipur, Chhattisgarh. The data collected were horizontal \& Vertical curvature of cornea which was done by manual keratometer for calculating intraocular lens power (after applying various formulas) to be implanted during cataract surgery. Then by using various statistical methods the results were interpreted.

Results: The total number of patients taken for the study were 600 and the total number of eyes were 600 , out of which 300 (50\%) were males and 300 (50\%) females, with the age ranging from 45 to 80 years. The mean corneal refractive power for the total sample were K1 (vertically) $44.18 \pm 1.89 \mathrm{D}$, K2 (horizontally) $44.74 \pm 1.88 \mathrm{D}$, ranges from $39 \mathrm{D}$ to $51 \mathrm{D}$. Although corneal refractive power was slightly higher in female as compared to male but the difference was not significant. The values were almost similar in right and left eyes.

Conclusion: The analysis might provide normative data for curvature of cornea required for IOL calculation in cataract patients of Chhattisgarh region. Data of the range will be useful as reference values in case the surgery is to be done at high volumes in surgical camps in rural areas where biometry equipment may not be available. There were no significant differences noted between male and female, right and left eyes in central Indian population.

KEY WORDS: Keratometry, Intraocular Lens Power, Cataract, Keratoconus, Keratoglobus, Marfan's Syndrome.

Address for Correspondence: Dr. Jagriti Agrawal, Associate Professor, Department Of Anatomy, Pt.J.N.M Medical College, Raipur Chhattisgarh, India. E-Mail: jagritiagrawal28@gmail.com

Access this Article online

Quick Response code

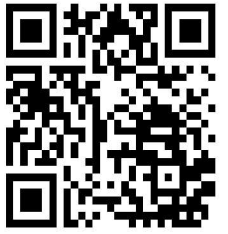

DOI: $10.16965 /$ ijar.2018.204

Journal Information

International Journal of Anatomy and Research

ICV for 2016 ISSN (E) 2321-4287 | ISSN (P) 2321-8967

90.30

https://www.ijmhr.org/ijar.htm

DOI-Prefix: https://dx.doi.org/10.16965/ijar

Article Information

Received: 26 Mar 2018

Peer Review: 26 Mar 2018

Revised: None
Accepted: 08 May 2018

Published (O): 05 Jun2018

Published (P): 05 Jun 2018

\section{INTRODUCTION}

The cornea is an important ocular structure involved in the mediation of visual perception. It is the most significant refractive surface of the eye, contributing approximately two thirds of the eyes refractive power [1].The total converging power of normal eye is slightly less than $+60 D$ and contribution of cornea in an average subject is about $+43 D$ [2]. Corneal refractive power is attributable to its shape and the relatively large difference between its refractive index (1.376) and that of air [1]. 
Vision can be significantly affected by relatively small changes in its structure and parameters. Measurement of corneal parameter is important in the diagnosis and management of ocular diseases such as keratoconus and glaucoma, fitting of contact lenses with refractive surgery such as LASIK laser, photorefractive keratectomy for myopic correction and also calculation of intra ocular lens power for cataract surgery [3]. The average values of dimensions of the optical components depends on race, age and gender [4].Keratometry estimates the radius of curvature, mean diopteric power (D) of cornea. It measures central 2-3 $\mathrm{mm}$ of the anterior cornea in main meridian (horizontal and vertical) and secondary calculation of the full optic power of the cornea [5] and expressed in Diopter (D) or mm of radius of curvature. Measurement of corneal refractive power can be done by variety of instruments such as keratometer, IOL Master or corneal topographer[6,7]. Higher corneal power are indicative of higher risk of Keratoconus [8]. A corneal curvature reading below $42 \mathrm{D}$ is also sign of an abnormal condition such as Marfan's syndrome[9].

The findings may provide information on the normal anatomy of the eye, be helpful for issues of corneal refractive surgery, and provide hints for diseases. This retrospective study was designed to evaluate the preoperative assessment of keratometry readings of Chhattisgarh population undergoing cataract surgery and set standards for adult old age central Indian population. In addition, the differences among the genders and the laterality were observed.

\section{MATERIALS AND METHODS}

This is a retrospective observational study conducted at private eye hospital in Raipur Chhattisgarh within a period of seven months from January17 to July 2017. A total of 600 patients comprising of 300 male and 300 female, age ranging from 45 to 80 years, complained of gradual painless diminution of vision were diagnosed as having senile mature or immature cataract in one or both the eyes and advised for IOL surgery were included for the study. Maximum number of patients were in the age group of 60 to 65 years. Straight forward senile cataract patient with no other ocular complications were included in the study.

After being informed consent had been obtained, keratometry was done with manual keratometer using Karl Zeis keratometer. Corneal refractive power was measured in both vertical (k1) and horizontal (K2) meridian in diopter. It can be converted to radius of curvature in millimeters after applying formula Diopter $=337.5 / R$ ( $r=r a-$ dius of curvature). Age, gender and laterality were also recorded as per the proforma. The data collected were analysed statistically. The objective of this study was to determine the average corneal refractive power in vertical and horizontal meridian of the Chhattisgarh population undergoing cataract surgery. This preliminary report will help in proper estimation of intra ocular lens power for post operative optimum visual outcome where the keratometry is not available and also provide normative value for corneal refractive power which is helpful in diagnosis of keratoconus, keratoglobus and helpful for contact lens fitting.

\section{RESULTS}

A total of 600 patients, out of which $50 \%$ male and $50 \%$ female age ranging from 45 to 80 years were included in the study. The mean $\pm S D$ keratometry reading $\mathrm{K} 1$ (vertical) and $\mathrm{K} 2$ (horizontal) of all cases were 44.18 $\pm 1.89 \mathrm{D}$ and $44.74 \pm 1.88 \mathrm{D}$ respectively.

Table 1: gender based descriptive statistics of keratometric readings.

\begin{tabular}{|c|c|c|c|}
\hline Parameters & Male & Female & Range \\
\hline $\begin{array}{c}\text { K-1 } \\
\text { (Mean+SD) }\end{array}$ & $43.91 \pm 1.87 \mathrm{D}$ & $44.45 \pm 1.91 \mathrm{D}$ & $39.5-50 \mathrm{D}$ \\
\hline $\begin{array}{c}\text { K-2 } \\
\text { (Mean+SD) }\end{array}$ & $44.39 \pm 1.91 \mathrm{D}$ & $45.1 \pm 1.87 \mathrm{D}$ & $39-51 \mathrm{D}$ \\
\hline
\end{tabular}

Table 1 shows gender based keratometric value in vertical ( $\mathrm{k} 1$ ) and horizontal curvature (K2) of anterior surface of cornea. In male the mean corneal refractive power in vertical meridian (K1) was $43.91 \pm 1.87 \mathrm{D}$ and in female $44.45 \pm 1.19$ $\mathrm{D}$, while horizontal corneal refractive power (K2) were $44.39 \pm 1.91 \mathrm{D}$ and $45.1 \pm 1.87 \mathrm{D}$ respectively in male and female. The mean keratometry readings in women was slightly, though not significantly, higher than men.

Table2 shows keratometric readings ranged from 39-51 D in right and left eyes, in male and 
Table 2: Gender based keratometric values in right and left eyes.

\begin{tabular}{|c|c|c|c|c|c|c|c|c|}
\hline \multirow{2}{*}{} & \multicolumn{4}{|c|}{ Male } & \multicolumn{4}{c|}{ Female } \\
\cline { 2 - 10 } & \multicolumn{2}{|c|}{ Right eye } & \multicolumn{2}{c|}{ Left eye } & \multicolumn{2}{c|}{ Right eye } & \multicolumn{2}{c|}{ Left eye } \\
\cline { 2 - 10 } & K-1 & K-2 & K-1 & K-2 & K-1 & K-2 & K-1 & K-2 \\
\hline Mean & 43.7 & 44.33 & 44.13 & 44.46 & 44.39 & 45.03 & 44.51 & 45.17 \\
\hline SD & 1.77 & 1.98 & 1.84 & 1.84 & 1.92 & 1.92 & 1.91 & 1.81 \\
\hline Range & $39-50$ & $39-50$ & $39.75-50$ & $40-49$ & $39.5-49.5$ & $39.5-50$ & $40.5-50$ & $41-51$ \\
\hline N & 150 & 150 & 150 & 150 & 150 & 150 & 150 & 150 \\
\hline
\end{tabular}

Table 3: Distribution of corneal curvature in male and female.

\begin{tabular}{|c|c|c|c|c|c|c|c|c|}
\hline \multirow{2}{*}{ Range } & \multicolumn{4}{|c|}{ Male } & \multicolumn{4}{c|}{ Female } \\
\cline { 2 - 10 } & \multicolumn{2}{|c|}{ Right eye } & \multicolumn{2}{c|}{ Left eye } & \multicolumn{2}{c|}{ Right eye } & \multicolumn{2}{c|}{ Left eye } \\
\cline { 2 - 10 } & K-1 & K-2 & K-1 & K-2 & K-1 & K-2 & K-1 & K-2 \\
\hline$<42$ & 27 & 18 & 24 & 19 & 15 & 10 & 17 & 9 \\
\hline $\mathbf{4 2 . 1 - 4 4}$ & 70 & 54 & 50 & 40 & 57 & 38 & 53 & 36 \\
\hline $44.1-46$ & 38 & 59 & 58 & 63 & 53 & 63 & 51 & 61 \\
\hline $46.1-48$ & 14 & 16 & 16 & 17 & 22 & 27 & 25 & 38 \\
\hline$>48.1$ & 1 & 3 & 2 & 2 & 3 & 12 & 4 & 6 \\
\hline
\end{tabular}

female both. In our study gender based keratometric values in right and left eyes were almost equal in male and female. In males, corneal refractive power mean \pm SD K1 (vertical) 43.7 $\pm 1.77 \mathrm{D}$, mean \pm SD K2 (horizontal) 44.33 $\pm 1.98 \mathrm{D}$ in right eye as compared to mean $\pm \mathrm{SD}$ $\mathrm{K} 1$ (vertical) $44.13 \pm 1.84 \mathrm{D}$, mean $\pm \mathrm{SD} \mathrm{K} 2$ (horizontal), 44.46 $\pm 1.84 \mathrm{D}$ in left eye. In female these values were mean \pm SD K1 (vertical) $44.39 \pm 1.92 \mathrm{D}$, mean $\pm S D$ K2 (horizontal) $45.03 \pm 1.92 \mathrm{D}$ in right as compared to mean $\pm S D K 1$ (vertical) 44.51 $\pm 1.91 \mathrm{D}$, mean \pm SD K2 (horizontal) $45.17 \pm 1.81 \mathrm{D}$ in left eye.

Table 3 shows distribution of corneal power in vertical meridian $\mathrm{K} 1$ and horizontal meridian $\mathrm{K} 2$. Readings were ranged from $39-51 D$.The maximum values of corneal refractive power in vertical and horizontal meridians falls between 4246D in male and female both. In male $\mathrm{K} 1-72 \%$, $\mathrm{K} 2-75 \%$ in right eye and in left these readings were $\mathrm{K} 1-72 \%$ and $\mathrm{K} 2-69 \%$ fall in between $42-$ 46 D. Similarly in female K1- 73\%, K2- 67\% in right eye and $\mathrm{K} 1-69 \%, \mathrm{~K} 2-64 \%$ in left eye fall between 42-46 D. Only 10 [1.67\%] patients had $\mathrm{K} 1$ and 23 [3.8\%] had $\mathrm{K} 2$ values more than $48 \mathrm{D}$.

\section{DISCUSSION}

Worldwide there has been a variation in the mean age of patient undergoing cataract surgery ranges from 45 to 80 years. Describing the normal range of the corneal refractive power is important in the choice of formula used for intra ocular lens $(\mathrm{IOL})$ power calculation in cataract surgery. Several factors influence the corneal refractive power, including age, sex, race, ethnicity and refractive status of the eye as well as certain anthropometric factors. In our study out of 600 cases, the mean $\pm S D$ keratometry readings $\mathrm{K} 1$ (vertical) and $\mathrm{K} 2$ (horizontal) were $44.18 \pm 1.89 \mathrm{D}$ and $44.74 \pm 1.88 \mathrm{D}$ respectively. Our study is quite similar with study from Hyderabad with keratometric values as K1: $44.00 \pm 1.83 \mathrm{D}$ and $\mathrm{K} 2: 44.78 \pm 1.88 \mathrm{D}[10]$ and population based study done in rural Central India the mean vertical corneal refractive power K1 was 44.62 $\pm 1.74 \mathrm{D}$ and the mean horizontal power K2 was $44.60 \pm 1.68 \mathrm{D}$ [11]. Also similar with study done by Mustafa et al[12] where mean values were $K 1 ; 43.46 \pm 1.68 \mathrm{D}$ and k2; $4.41 \pm 1.98 \mathrm{D}$. A study from Swat reported the mean $\mathrm{K} 1$ as $42.48 \pm 2.17 \mathrm{D}$ and the mean $\mathrm{K} 2$ as $42.65 \pm 2.10 \mathrm{D}$, lower than ours mean[13]. In the study from Western Nepal observed values were $\mathrm{K} 143.64 \pm 1.45 \mathrm{D}$ and $\mathrm{K} 2$ 44.29 $41.47 \mathrm{D}$ respectively, it is quite similar with our findings[14].The readings obtained were almost similar, but the small amount of discrepancies could be due to the type of instrument used for calculation, sample size, racial and genetic factor also play important role.

Gender based comparison of the corneal curvature readings in our study found higher $\mathrm{K} 1$ and 
$\mathrm{K} 2$ in females than males but the difference was not significant. The mean $\pm S D$ K1 in male

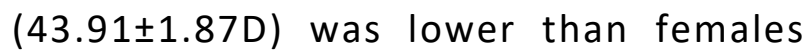
(44.45 $\pm 1.91 \mathrm{D})$. The mean \pm SD K2 for male (44.39 \pm 1.91D) was lower than in female (45.1 $\pm 1.87 \mathrm{D})$. There has been variability in the mean keratometric value among Pakistani population (K1-44.00 D, K2-44.78 D and K1-42.65 D, K2$42.48 \mathrm{D}) \mathrm{K} 1$ in male $43.68 \pm 1.80 \mathrm{~K} 2-44.47 \pm 1.81 \mathrm{D}$ while in female k1- $44.31 \pm 1.80 \mathrm{D} k 2-45.05$ \pm 1.89 D. $[10,13]$.

Similar gender based comparison reported earlier by Mustsfa hameed [12] in Rawalpindi, where mean keratometry readings were significantly higher in females as compared to males. K1 in males: (42.95 $\pm 1.54 \mathrm{D})$, Females: (43.88 $\pm 1.67 D)$. The mean \pm SD K2 for male $(43.9 \pm 1.66 \mathrm{D})$ was significantly lower than female $(44.78$ $\pm 1.70 \mathrm{D})$. Similar differences were found in population based central indian eye study in Maharastra in which the mean vertical corneal refractive power $\mathrm{K} 1$ was $45.02 \mathrm{D} \pm 1.67 \mathrm{D}$ in female versus $44.18 \pm 1.72 \mathrm{D}$ in male, K2 $44.9 \pm 1.6 \mathrm{D}$ in female versus $44.27 \pm 1.71 \mathrm{D}$ in male [11]. Also reported that the horizontal and vertical corneal refractive power not vary significantly between right and left eyes) Gender differences in ocular biometry among cataract patients of western Nepal from Shrishti Shreshtha [14] found deeper corneas in female K1 $43.79 \pm 1.51 \mathrm{D}, \mathrm{K} 244.41 \pm 1.54 \mathrm{D}$ compared to male K1 $43.51 \pm 1.4 \mathrm{D}, \mathrm{K} 244.6 \pm 1.4 \mathrm{D}$.

Most of the Keratometric values in adult population aged 40 to 81 years having relatively steeper corneal curvature in female due to short axial length and shorter stature and partly due to genetic and environmental factor between men and women. Female subjects may also experience some physiological changes due to menstruation which could affect their ocular dimensions at the time of the study (Lam \& Loran 1991) [15].

In our study $38.33 \%$ of $\mathrm{K} 1$ values fell in between $42-44 D$, and $41 \%$ having horizontal corneal power K2 between 44-46 D while Muhammad Saleem [16] found the dioptric power of vertical meridian (K1) 37-48 D and the same was the case with horizontal meridian of cornea (K2). Majority of $\mathrm{K} 1$ readings fall between 42-44 D (45\%) and majority of $\mathrm{K} 2$ readings between
42-44 were (49\%). Rashid13 noticed $40.84 \%$ of cases between $42-44 \mathrm{D}$ for $\mathrm{K} 1$ and $41.20 \%$ between 42-44 D in case of K2 readings. Naz[17] noted $42.5 \%$ cases of $K 1$ between $42-44 D$ and $27 \%$ cases of $K 2$ between $42-44 D$, this was also comparable to the study done by Siahmed K, et al'[18] Asif lqbal et al.[19].

\section{CONCLUSION}

Normal values of corneal refractive power for central Indian were established at the end of this study. The differences in corneal refractive power could be attributed to the difference in gender and race. The results will serve as future reference for eye care practitioners in making clinical decisions and management of patients particularly in central India.

\section{Conflicts of Interests: None}

\section{REFERENCES}

[1]. Ruskell GI, Bergmanson JPG. Anatomy and physiology of the cornea and related structures. In: phillip aj, speedwell I, eds. Contact lenses. 5th ed. Oxford: butterworth-heinemann, 2006.

[2]. Duke-Elder, S., 1970, system of ophthal., alway, 5, 240 henry kimmpton, london,

[3]. P. Mashige. A review of corneal diameter, curvature and thickness values and influencing factors. african vision and eye health; south african optometrist: 2013;72(4):185-194. Doi: 10.4102/ aveh.v72i4.58

[4]. Wojciechowski R, Congdon N, Anninger W, Teo Broman A. Age, Gender, Biometry, refractive error, and the anterior chamber angle among alaskan eskimos. Ophthalmology 2003;110:365-75.

[5]. Kanski jj. Clinical ophthalmology, a systemic approach, $5^{\text {th }}$ ed. Edinburgh: butterworth- heinemann, 2003.

[6]. Seitz B, Langenbucher A, Zagrada D, Budde W, Kus MM. Corneal dimensions in patients with various types of corneal dystrophies and their impact on penetrating keratoplasty. Klin monatsbl angenheilkd 2000;217:152-158.

[7]. Denniston Ako, Murray Pi. Oxford handbook of ophthalmology (oup), 2nd ed. Oxford: oxford university press, 2009.

[8]. Fam Hb, Lim KL. Meridional analysis for calculating the expected spherocylindrical refraction in eyes with toric intraocular lenses, j cataract refract surg. 2007 dec;33(12):2072-6.

[9]. Heur M, Costin B, Crowe S, Grimm RA, Moran R, Svensson LG, Traboulsi El. The value of keratometry and central corneal thickness measurements in the clinical diagnosis of Marfan syndrome. American journal of ophthalmology. 2008 Jun 1;145(6):9971001. 
[10]. Nizamani NB, Surhio SA, Memon S, Talpur KI. Axial length variability in cataract surgery. Journal of the college of physicians and surgeons pakistan. 2014;24(12):918-921.

[11]. Nangia V, Jonas JB, Sinha A, Matin A, Kalkarni M, Panda-Jonas $\mathrm{S}$. Ocular axial length and its associations in an adult population of central rural india: the central india eye and medical study. Ophthalmology 2010;117(7):1360-66.

[12]. Mustafa Abdul Hameed Ismail, Sabeen Chaudhry. Keratometry, axial length and intra-ocular lens power variations observed during biometryisra medical journal 2015;7(3).

[13]. Rashid H, Naseem A, Rahman F. Two years review of intraocular lens power calculation in ophthalmology department of saidu teaching hospital, swat. Pak j Ophthalmol 2007;23(3):122-25.

[14]. Shristi Shrestha, Khem Raj Kaini, Binamra Basnet. Gender differences in ocular biometry among cataract patients of western Nepal. american journal of public health research, 2015;3(4a):31-34.

[15]. Lam, C.S.Y. \& Loran, D.F.C. Designing contact lenses for oriental eyes. J br contact lenses assoc. 1991;14(3):109-114.
[16]. Saleem M, Khan Sb, Khattak Ma, Muhammad L. Analysis of intra ocular lens power estimation in patients admitted for cataract surgery. Gjms 2009;7(9): 22-26.

[17]. Naz Ma. Review of 1100 cataract cases reported at the ophthalmic clinics in military hospital rawalpindi and combined military hospital lahore. Pak j ophthalmol 2004;20:143-7.

[18]. Siahmed K, Muraine M, Brasseur G. Optic biometry in intraocular lense calculation for cataract Surgery, comparison with usual methods. J fr ophthalmol 2001;24:922-6.

[19]. Asif Iqbal, Muhammad Idrees, Bilal Bashir, Mubashir Rehman, Omer Khan Orakzai. Biometric assessment and intraocular lenspower calculation in adults. J med. Sci. (peshawar, print) july 2014;22(3):126-128.

\footnotetext{
How to cite this article:

Jagriti Agrawal, Pawan Kumar N, Pradep Jain. ANTHROPOMETRIC MEASUREMENT OF CORNEAL CURVATURE BY KERATOMETRY IN ADULT CENTRAL INDIAN POPULATION. Int J Anat Res 2018;6(2.3):5346-5350. DOI: 10.16965/ijar.2018.204
} 